\title{
Investigation of the Accumulation of Greenhouse Gases in Terms of Road Traffic Gradients
}

\author{
Zaydoun AbuSalem, Nabil Hazim, Nawal Louzi
}

\begin{abstract}
This research reflects on the impacts of traffic factors, car acceleration, volume of traffic, road gradient and the resulting sum of air pollutants, with a significant impact on the emissions of the vehicles. The general and detailed urban plans are normally addressed to these factors. Such considerations usually determine the adverse effects of motor vehicles, and environmental hazards, such as air pollution and vibration, which affects highways and bridges. However, the effect of road transport and preparation on the ecosystem is described. The research focuses on climate aspects that can be identified and designed so that all generic proposals can include them. In this study, $\mathrm{CO}, \mathrm{NO}_{2}, \mathrm{TVOC}$ 's and $\mathrm{SO}_{2}$ concentration at multiple sampling sites were screened regularly. The study revealed that air pollutant rates are highly correlated with traffic movement and prevailing gradients. The $\mathrm{SO}_{2}, \mathrm{NO}_{2}, \mathrm{CO}$ and TVOC's concentrations were very much associated to significant road flow parameters such as traffic elevation, intensity and amount of transport.
\end{abstract}

Key Words; transport, emission, pollutant, gradient, speed, traffic volume, road gradient

\section{INTRODUCTION:}

The environmental pollutant emissions from road traffic are now a grave concern for drivers who expend substantial time on the road. In many cities worldwide, air pollutants have increased significantly as vehicular traffic has grown at crowded times. Amman has lately become host to many refugees from neighboring countries owing to instability in the country. The refugee influx has turned into harmful air pollutants. Engines emit toxins such as NOx, carbon monoxide and volatile organic substances (VOC's) as well as particulate matter (PM). Motor vehicles emit pollutants; such pollutant amounts are caused by a number of factors. M. A and Zickus. Greig, 2003, has shown that the amounts of contaminants depend largely on the pollution rates of the engine, the atmosphere and greenhouse gas levels in the environment. Joumard, 1999, reported that the exhaust emissions of automobiles differ between operating modes, acceleration, decelerating and idling. The effect of traffic flow dynamics at CO levels was studied at Marsden and others in 2001. Others observed that kinds or size of vehicle may also impact emissions of pollutants. Passenger vehicles, light-sized buses, high-speed trucks and motorsports have been shown to release toxins at varying rates in the environment.

Revised Manuscript Received on October 20, 2020.

* Correspondence Author

Zaydoun AbuSalem*, Department of Engineering, Khawarizmi University Technical College, Amman, Jordan, E-mail: z.abusalem@khawarizmi.edu.jo

Nabil Hazim, Department of Civil Engineering, Al-Ahliyya Amman University, Amman, Jordan, E-mail: n.hazim@ammanu.edu.jo

Nawal Louzi, Department of Civil Engineering, Al-Ahliyya Amman University, Amman, Jordan, E-mail: n.louzi@ammanu.edu.jo

(c) The Authors. Published by Blue Eyes Intelligence Engineering and Sciences Publication (BEIESP). This is an open access article under the CC BY-NC-ND license (http://creativecommons.org/licenses/by-nc-nd/4.0/)
Vehicles' air pollution relies on acceleration and velocity. Several studies have chosen to use pollution indicators based on average speed. The rate of polluting air pollution is also impacted by vehicle age and accumulated kilometers, the type of fuel used, the ambient temperature, precipitation or wind. The state of the car's servicing and the addition and quality of emission control devices can also influence the emission levels. Kai Zhang et al. conducted research in 2014 of the effect of vehicular traffic on emissions and on health risks. In 2017 Katarjna B conducted a study on the effects of the property of car transport in Poland on overall emissions. In 2017, after the construction of a new road in Montreal Canada, Shohel et al conducted a study on increased air pollution from traffic volume, finding that concentration in NO2 has been decreased due to lower traffic. No analysis of the sort and other feature on which this paper focuses have been performed. The pollution level for light-duty (LDGV) gasoline vehicles reported by the Environmental Protection Agency (EPA) for TVOC's is $2.683 \mathrm{~g} / \mathrm{hr}$, THC is $3.163 \mathrm{~g} / \mathrm{hr}$, CO is $71.225 \mathrm{~g} / \mathrm{hr}$, and for NOx is $3.515 \mathrm{~g} / \mathrm{hr}$.

Air pollution has a global concern because of its unwilling pronounced welfare effects on human and the living beings in the world. Lead, heavy metals, Diesel particulates, Nitrogen oxides, Photochemical oxidants (such as Ozone), NOx and SOx are considered the most major pollutants that emissions from motor vehicles exhaust. The vehicular speed, traffic volume, and longitudinal road (vertical) grades have a great effect on vehicle emission and air pollution quantity for the same passenger trip distance.

Seven Major Pollutants of Concern; they are Particulates, Sulfur Oxides (SOX), Ozone (O3), Nitrogen Oxides (NOX), Carbon Monoxide (CO and other hydrocarbons), Volatile Organic Compounds (VOCs), Lead (\& others: mercury, other inorganic metals, radon, and $(\mathrm{HCl})$. Figure 1. represents the National Emissions Inventory from the Environmental Protection Agency EPA as the Mobile Sources Contribute approximately $60 \%$ of total air pollution.

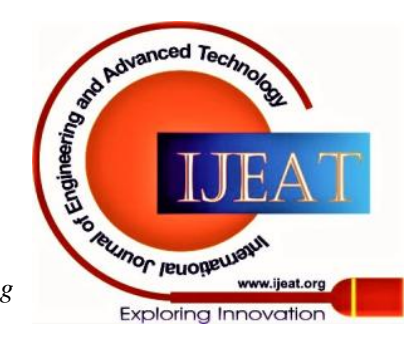




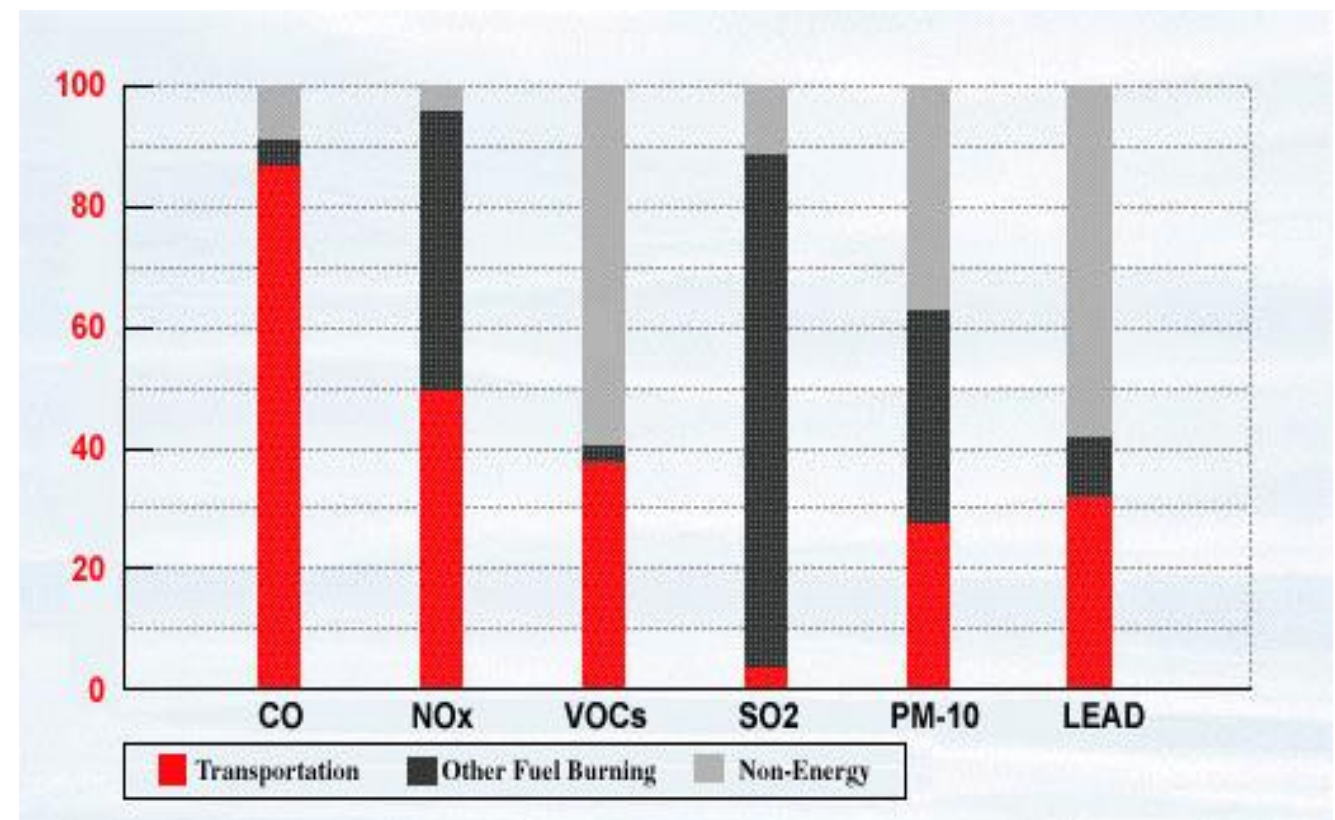

Figure 1. National Emissions Inventory from EPA (Mobile Sources Contribute approximately $60 \%$ of total air pollution)

In 1998, it was reported in Canada that gas or diesel combustion of the motor of the automobile is at the root of the major air pollutants which are both $\mathrm{NO} 2$ and $\mathrm{CO}$, whereas PM10 and Sulphur dioxide (Noor et al 2006) were reported in Sydney in addition to Rogak et al. While, automatic reporting means that environmental pollutants such as ozone and carbon Monoxide are collected. A quantitative study on air polluting emissions on roads in Jordan as a function of and vehicle type of cars has been performed in 2005 by Abo-Qudais and AL-Momani et al. in 2015. It has therefore been clearly identified that vehicle size, traffic volume and route elevation are variables that affect greenhouse gases. Excessive concentrations of air pollutants are easily accumulated which have a serious effect on drivers' health, especially when operating vehicles for a long time period. These results are important since gaseous air pollutants combines easily more than oxygen with the hemoglobin in blood and reduces the content of oxygen in the blood of exposed drivers. Therefore, the health risk is elevated due to the long exposure time of drivers in the high grades.

\section{MATERIALS AND METHODS:}

The accumulation of air pollutants in vehicle speed, traffic density and road slope is analyzed in this report. The CO, NO2, TVOC's and SO2 emissions are reported for a number of times which include peak times in a number of places in the four monitoring sites, samples of air pollutant SO2, NO2, CO and TVOC's are made. These sampling stations are shown in Table 1 in terms of their geographical characteristics.

Table 1. Geographical attributes for sampling

\begin{tabular}{|c|c|c|c|c|}
\hline Location & Road Grade (\%) & Eastern coordinates & $\begin{array}{c}\text { Northern } \\
\text { coordinates }\end{array}$ & $\begin{array}{c}\text { Elevation } \\
(\mathrm{m})\end{array}$ \\
\hline 1 & 0 & 35.8385881 & 32.03155514 & 920.7 \\
\hline 2 & 5 & 35.8424156 & 32.02426216 & 992.8 \\
\hline 3 & 7 & 35.8335900 & 32.03302000 & 892.6 \\
\hline 4 & 9 & 35.8341400 & 32.03736000 & 839.7 \\
\hline
\end{tabular}

Generally, the factors affect the pollution concentration in car, and two half PCU is the motorcycle. The broad number urban highways are divided into four groups; traffic parameters, geometric design, atmospheric condition, and the surroundings (background) concentration. In a particular place, concentrations are typically based on average traffic speed and road gradient. Observations of these essential variables were therefore included in the project. Such calculations are carried out at the same sites with an average of fifteen minutes for the traffic density. The appliances used for air greenhouse gas readings are primarily the Toxic Gas Data logger based on the NO2 Electro-Chemical Cell mechanism and the Total Volatile Organic Compounds TVOC's photo ionization detection (PID). The NO2, CO and SO2 concentration levels is $0.02,0.5$ and $0.1 \mathrm{ppm}$. For all tests, the devices used were calibrated. Traffic density in passenger cars per hour (PCU/hr) was reported at the time of the measurement. Two PCU vehicle a unit is the passenger of busses and trucks correlates to 3 PCUs. The first device for measuring greenhouse gases is the Toxic Gas Analyzer, used using the NO2 nitrogen cell electrochemical method, while the $0.02,0.5$ and $0.1 \mathrm{ppm}$ photo ionizing (PID) picture ionizing (PID) is used for the TVOC's Total Volatile Organic Substances. For all tests, the instruments used were calibrated. The measurement used to reflect the capability of the highway is reputed as the PCU for passenger vehicles in which a car is a unit while a vehicle is a half unit. Bus and lorries are equal to 3 PCUs due to their large scale. The number of vehicles crossing the road during a certain time frame is defined as the total number of vehicles.

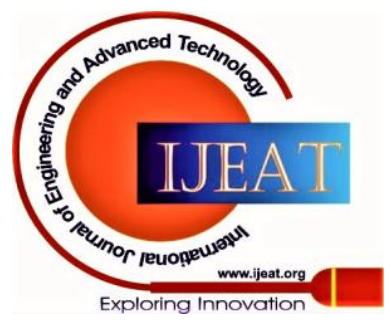




\section{RESULTS AND DISCUSSION:}

In terms of the traffic car units an hour and $0 \%, 5 \%, 7 \%$ and 9\%, as defined in Figures 2, 3, 4, and Figure 5 of the best fit straight line. The concentrations of gas contaminants were measured by the influence of the road slope. For e.g., the number of passenger cars is approx. 1000 (PCU / h). The short-term (15-minute average) measurements effects of gaseous emissions (SO2, NO2, $\mathrm{CO}$ and TVOC's) for road gradients $0 \%, 5 \%, 7 \%$ and $9 \%$ show in Figure 6 . The ratio of the road gradient with the vehicle speed with traffic volumes for the different grades as shows in Figure 7.

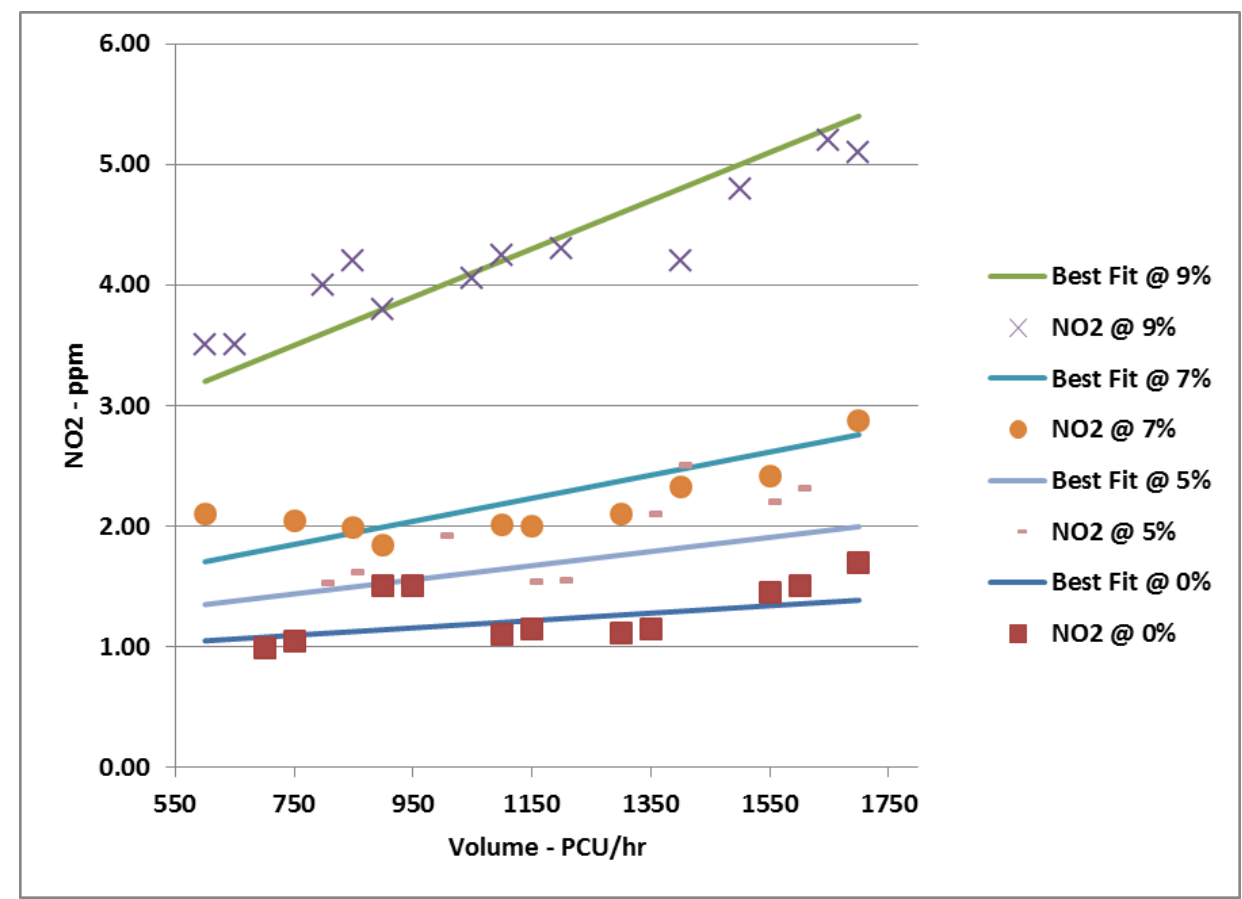

Figure 2. Pollutant Concentration Variations with Road Gradients for $\mathrm{NO}_{2}$

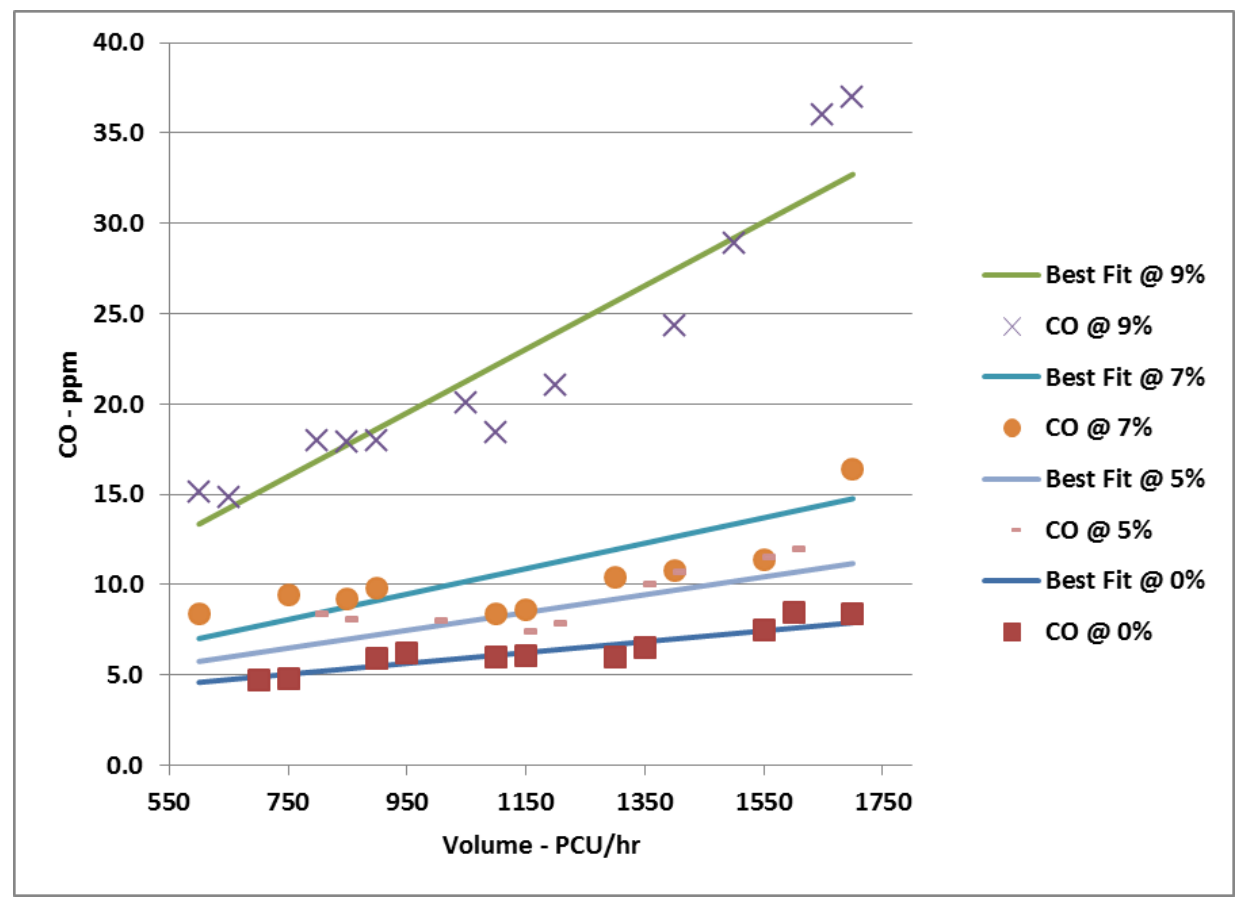

Figure 3. Pollutant Concentration Variations with Road Gradients for CO

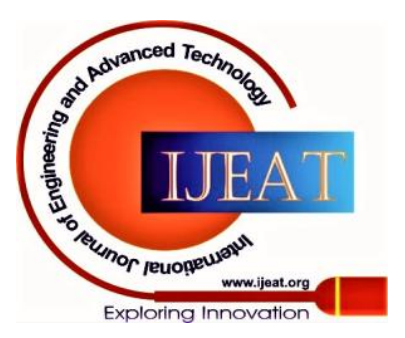


Investigation of the Accumulation of Greenhouse Gases in Terms of Road Traffic Gradients

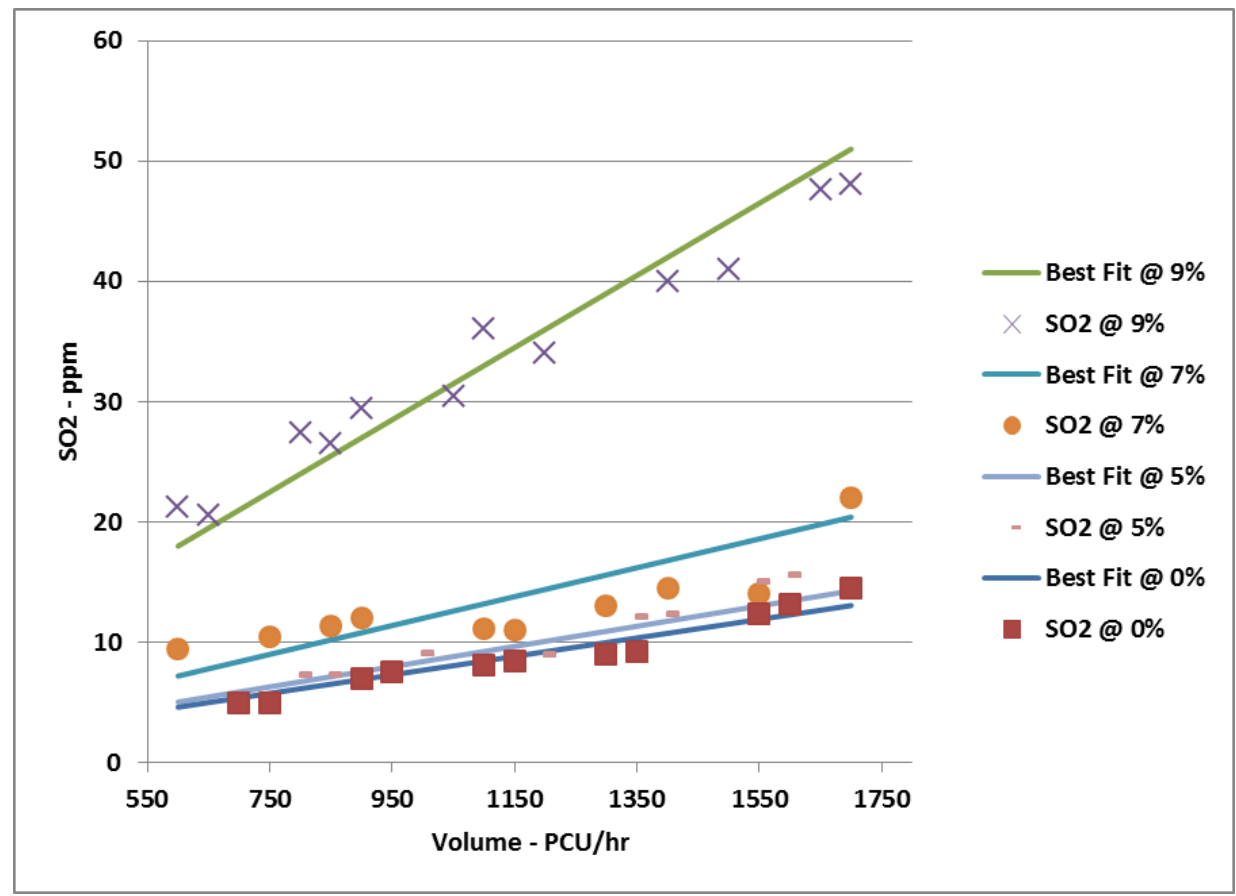

Figure 4. Pollutant Concentration Variations with Road Gradients for $\mathrm{SO}_{2}$

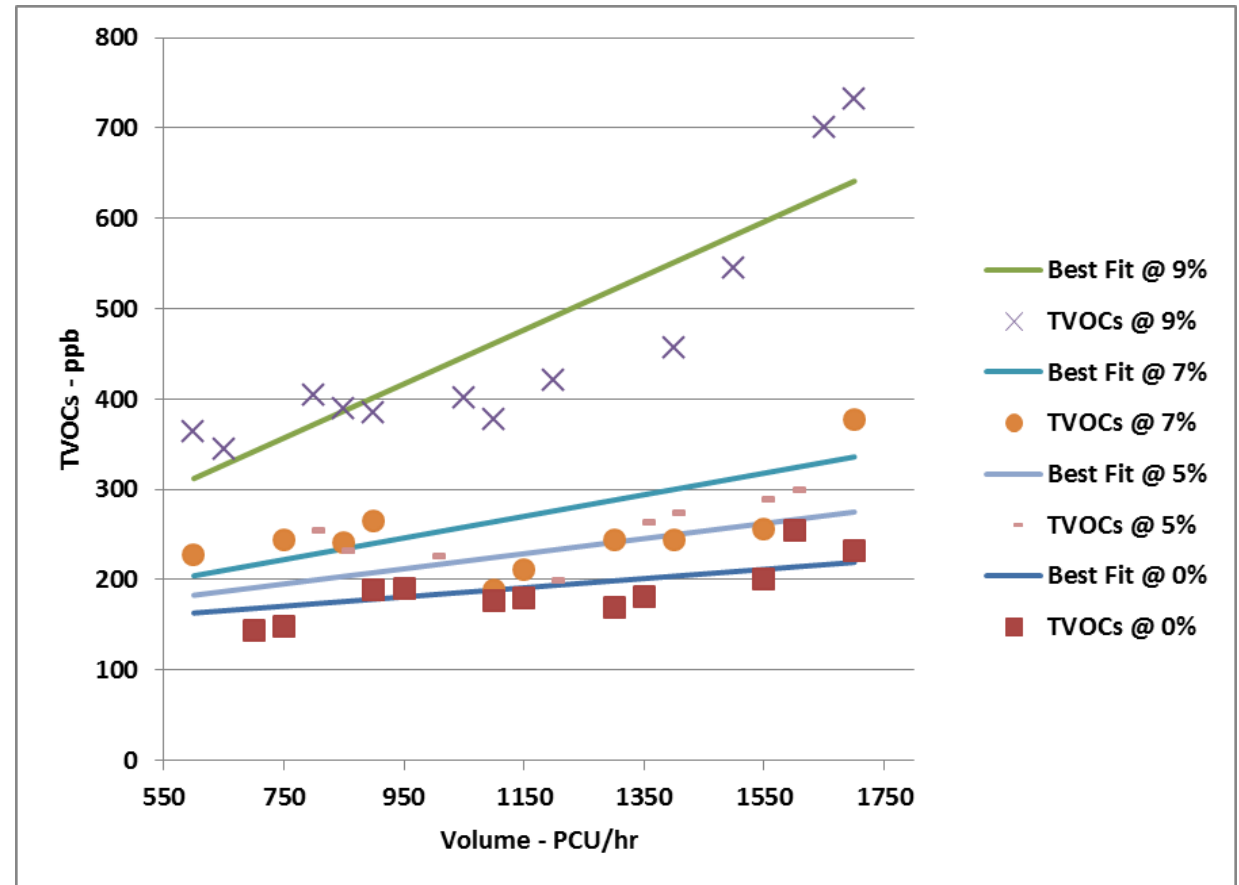

Figure 5. Pollutant Concentration Variations with Road Gradients for TVOC's

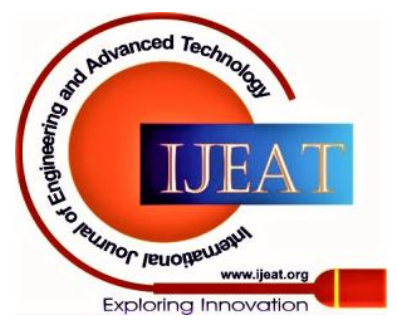



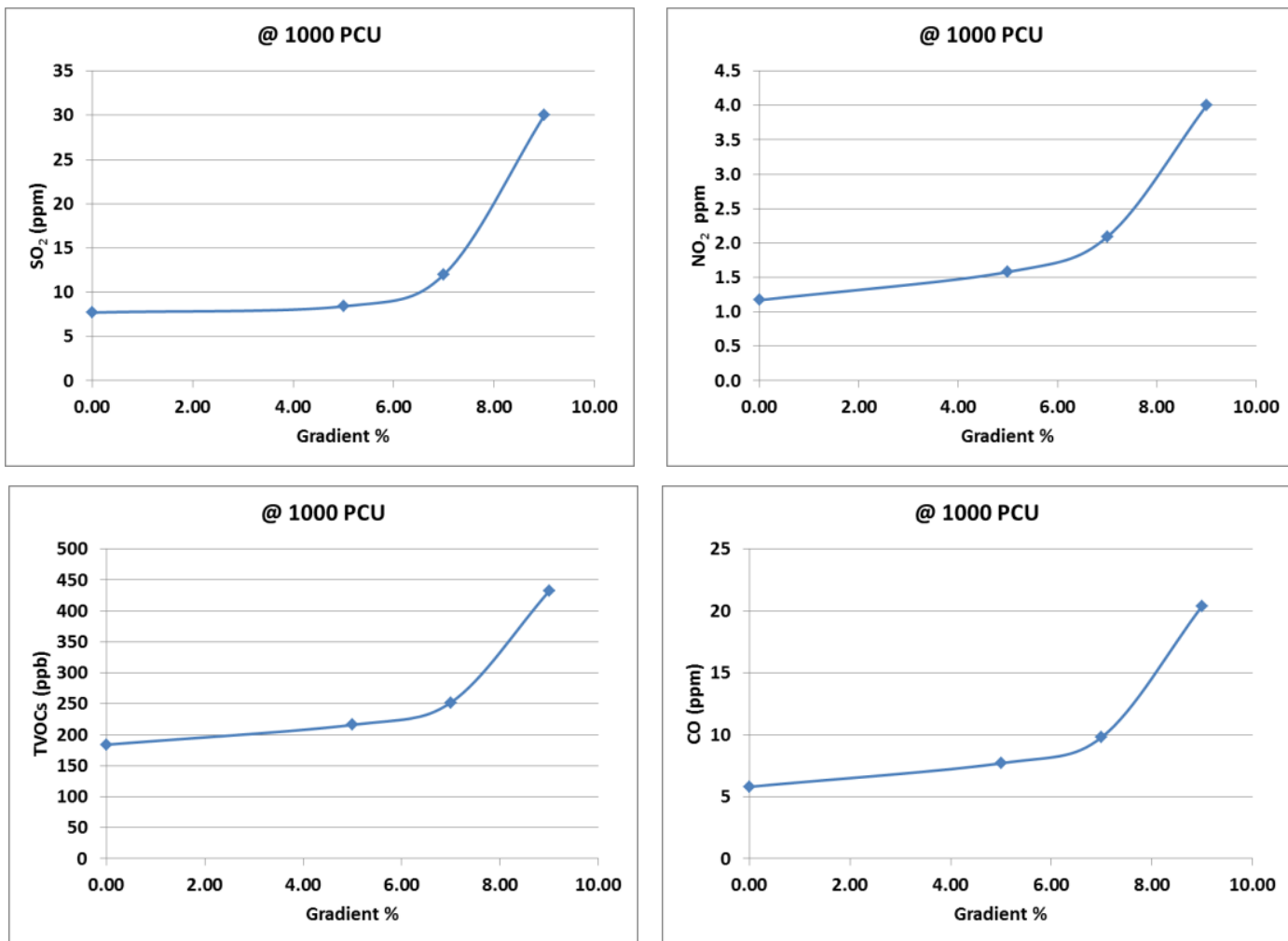

Figure 6. $\mathrm{NO}_{2}, \mathrm{CO}, \mathrm{SO}_{2}$, and TVOC's Variations with Road Gradient at $1000 \mathrm{PCU} / \mathrm{hr}$ volume.

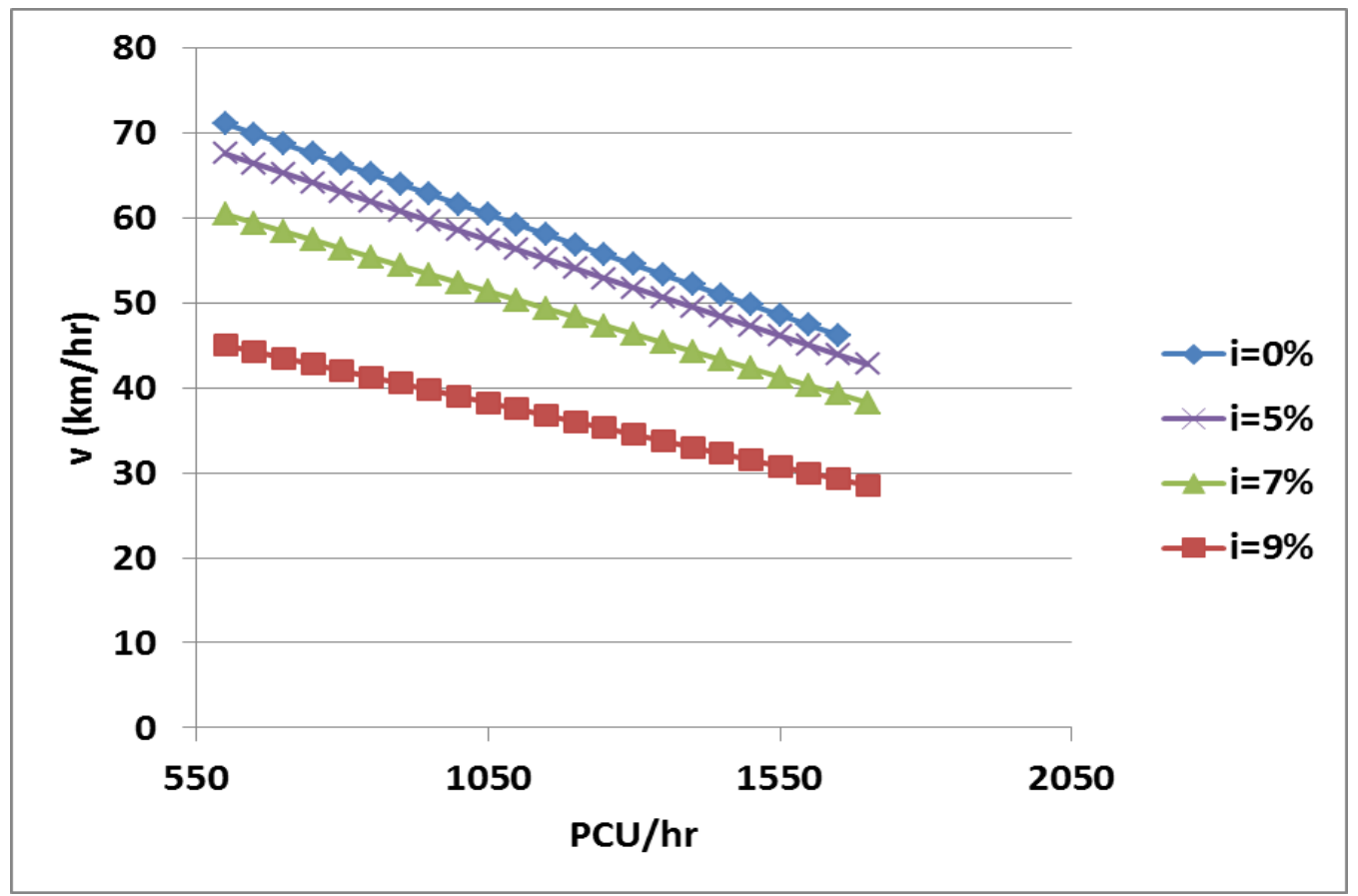

Figure 7. Best Fit Average Velocity Vs Road volumes with Grades.

The slope indicates that the road and air movement are highly influenced. Figure 7 indicates that, in relation to traffic flow, the volume falls in the upper part of the curve. This linear relationship from the figure also reveals the $\mathrm{R}$ values square for the densities of greenhouse gases $\mathrm{SO} 2$, NO2, Co and TVOC's whereas the speed of traffic is shown in the semi-log plots as the following;

$$
\begin{array}{ll}
\text { TVOC's }=11.65 \mathrm{~V}+875.4 & \text { with } \mathrm{R}^{2}=0.98 \\
\mathrm{SO}_{2}=1.04 \mathrm{~V}+68.6 & \text { with } \mathrm{R}^{2}=0.97 \\
\mathrm{NO}_{2}=0.18 \mathrm{~V}+8.8 & \text { with } \mathrm{R}^{2}=0.99 \\
\mathrm{Co}=0.70 \mathrm{~V}+47.3 & \text { with } \mathrm{R}^{2}=0.99
\end{array}
$$

The change of pollutants emissions of vehicles is correlated to the vehicle regularity in speeding up and accelerations. During a short period of time, the variability in the time distribution of gaseous ambient air pollutants was reported and did not universally striving the time distribution, for example, when in this analysis, the variance in NOx and $\mathrm{VPH}$ reflected the same findings as stated by Joumards in 1999.

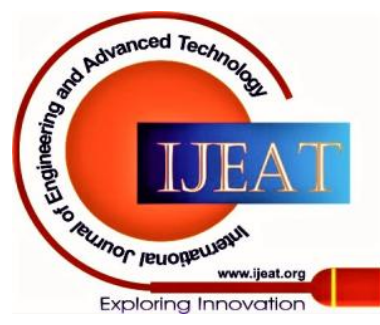




\section{Investigation of the Accumulation of Greenhouse Gases in Terms of Road Traffic Gradients}

The average pollutant rate per gradient can be defined as given in the following equation:

$\mathrm{APR} / \mathrm{G}=($ Emissions at $10 \% /$ Emissions at $0 \%)$

Where,
APR/G: the average pollutant rate per gradient which is used as an estimated linear average of pollutant concentration per a unit gradient percentage. Table 2 shows the APR/G values for the concentration of SO2, NO2, CO and TVOC's by using APR/G equation.

Table 2. Maximum ratios of gaseous pollutants emissions with grades

\begin{tabular}{|c|c|c|c|c|}
\hline Pollutant & $\mathrm{SO}_{2}$ & $\mathrm{NO}_{2}$ & $\mathrm{CO}$ & TVOC's \\
\hline APR/G (Ratio) & 3.1 & 2.8 & 2.5 & 5.2 \\
\hline
\end{tabular}

The disparity in SO2 levels at different gradients is fantastic since there is no restriction on road travel for buses and trucks despite low SO2 pollution for these heavy-duty vehicles. In comparison, the $\mathrm{NO} 2$ levels of the various grades were roughly 2.8 , whereas the $\mathrm{CO} 2$ ratio was 2.5 . It is assumed that the specific gradient and traffic movement with a higher nitrogen dioxide is influenced by the amount of NO2 and CO for a higher slope.

After evaluating the relationship between the air quality and traffic flow data with a linear regression at different gradients, it is apparent that the contaminant concentrations rise with an increase in gradients.

Depending on the approximate linkages amongst SO2, NO2, CO and TVOC's pollution concentrations, different distinctive traffic flow impacts can be established on concentrations of air pollutants on highways. Lower pollutant accumulation was observed under high gradient traffic flow circumstances with traffic speeds below $50 \mathrm{~km} /$ h. The results are similar to the studies. More speeds also lead to lower concentrations of SO2, NO2, CO and TVOC's to $60 \mathrm{~km} / \mathrm{h}$. It was also noticed that traffic speeds were significantly lower, leading to a lower traffic levels at fairly high gradients, and therefore increased levels of gaspollutant.

This study showed, in summary, that the trends of circulation significantly affect the levels of air pollution and vary under different gradients and volumes of traffic. These impacts should be considered to analyze uncertainty and cultivate confidence restrictions for systems for dispersion of emissions and to develop the system for an effective adjustment in air quality.

\section{CONCLUSIONS:}

In this analysis, air pollutant properties were evaluated under various conditions of traffic and road gradients; throughout prevailing conditions of traffic, $\mathrm{SO}_{2}, \mathrm{NO}_{2}, \mathrm{CO}$, TVOC's levels were calculated. The levels of $\mathrm{SO}_{2}, \mathrm{NO}_{2}, \mathrm{CO}$ and TVOC's were between 2.5 and 5.2 on various road gradients. The air contaminant amounts had a strong correlation with traffic flow and path gradient. The Rsquare magnitude and the traffic levels are shown on the plots in Figure 5 in relation to $\mathrm{SO}_{2}, \mathrm{NO}_{2}, \mathrm{CO}$ and TVOC's concentration. It has been assumed that the amounts of the pollutant decrease to a pace of up to $60 \mathrm{~km} / \mathrm{h}$, whereas the increasing levels were observed under the same flow. The average pollutant concentration per gradient parameter was used in this analysis. The values acquired are very much in line with the local conditions that in other recent studies by other scientists are not typical compared to other measuring locations. Distinctions may therefore be incorrect with other studies.

\section{REFERENCES:}

1. AL-Rousan, Ammar A. et al. "Urban Traffic Pollution Reduction for Certain Cars Using Petrol Engines by Hydro-Oxide Gas Induction" Journal of Air \& Waste Management Association 65[12]: 1456-1460, [2015].

2. Berggren, Christian, Thomas Magnusson," Reducing automotive emissions", The potentials of combustion engine technologies and the power of policy, Energy Policy, Volume 41, 2012, pages 636-643,

3. Chih Ming Ma, Gui Bing Hong, Chang Tang Chang, "Influence of Traffic Flow Patterns on Air Quality inside the Longest Tunnel in Asia", Aerosol and Air Quality Research,11: 44-50, [2011].

4. Duffy, B.L. and Nelson, P.F., "Non-methane Exhaust Composition in the Sydney Harbour Tunnel: A Focus on Benzene and 1, 3butadiene". Atmos. Environ. 30: 2759-2768, [1996].

5. Joumard, R'Estimation of Pollutant Emissions from Transport', ISBN 92-928-6785-4, Luxembourg, p. 175. Available on the Web at: [1999].

6. Kai Zhanga and Stuart Battermanb, "Air pollution and health risks due to vehicle traffic" Sci Total Environ. 2013 Apr 15; 0: 307-316.

7. Katarzyna Bebkiewicz1, Zdzisław Chłopek2, Krystian Szczepański3, Magdalena

8. Zimakowska-Laskowska4 "The Influence of the Properties of Vehicles Traffic on the Total Pollutant Emission" Proceedings of the Institute of Vehicles 1(110), [2017\}

9. Lonneman, W.A., Selia, R.L. and Meeks, S.A., "Non methane Organic Composition in the Lincoln Tunnel". Environ. Sci. Technol. 20:790-799, [1986].

10. M. Zickus and A. Greig, "Effect of congested vs. freeway urban traffic flow on air pollutant concentrations in a street canyon". 7th Int. Conf. on Harmonization within Atmospheric Dispersion Modelling for Regulatory Purposes, [2003].

11. Marsden, G., Bell, M., Shirley R., "Towards a real-time microscopic emissions model", Transportation Research Part D, Vol. 6, pp. 37-60, [2001].

12. Norazian Mohamed Noor, Ahmad Shukri Yahya, Nor Azam Ramli, Mohd Mustafa Albakri Abdullah, "Using the Linear Interpolation Technique to Estimate Missing Values for Air Pollution Data", Proceeding of Malaysian University Colleges Seminar on Engineering and Technology [MUCET], [2006].

13. Pierson, W.R., "Real-world Automotive Emissions-Summary of Studies in the Fort McHenry and Tuscarora Mountain Tunnels". Atmos. Environ. 30: 2233-2256, [1996].

14. Rogak, S.N., Green, S.I. and Pott, U., "Use of Tracer Gas for Direct Calibration of Emission-factor Measurements in a Traffic Tunnel". J. Air Waste Manage. Assoc.48: 545-552, [1998].

15. Saad Abo-Qudais et al. "Performance Evaluation of Vehicles Emissions Prediction Models". Clean Technology and Environmenta Polices, Vol71s.4, pp 279-284. November [2005].

16. Shohel Reza Amin,1 Umma Tamima,2 and Luis Amador Jimenez "Understanding Air Pollution from Induced Traffic during and after the Construction of a New Highway: Case Study of Highway 25 in Montreal" Journal of Advanced Transportation Volume 2017, Article ID 5161308, 14 pages

17. Talal M. AL-Momani et al. "Emission Rate of Gases Emitted from Private Gasoline Vehicles in Irbid-Jordan" Jordan Journal of Civil Engineering, Vol.5, No. 2, [2011].

18. Talal M. AL-Momani. "Exhaust Emissions and Environmental Case Study: German Gasoline Vehicles" Dirasat, Pure Sciences, Vol. 33 , No. 1, [2006].

Blue Eyes Intelligence Engineering
Published By

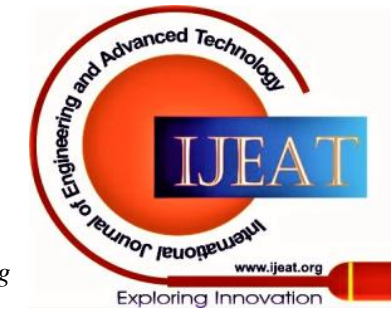

(C) Copyright: All rights reserved. 